\title{
Effectiveness of Supraomohyoid Neck Dissection in Oral Cancers with N1 Neck
}

${ }^{1}$ TR Harshita, ${ }^{2}$ SM Azeem Mohiyuddin, ${ }^{3}$ A Sagayaraj, ${ }^{4}$ TN Suresh, ${ }^{5}$ Shuaib Merchant

\begin{abstract}
Aim: Lymph node metastasis in squamous carcinoma of oral cavity carries poor prognosis. Majority of patients in our country present with locally advanced malignancy which has high incidence of micrometastasis. A comprehensive neck dissection in patients with $\mathrm{N} 0$ and $\mathrm{N} 1$ neck is overkill with resultant morbidity. Lymph node metastasis from oral cavity has predictable pattern. Supraomohyoid neck dissection (SOND) is a one stage treatment and staging procedure in patients with locally advanced oral cancer with N0 and N1 neck.
\end{abstract}

Materials and methods: We are presenting a series of 117 patients with malignancy of oral cavity with $\mathrm{N} 1$ neck who underwent SOND, majority involved buccal mucosa. Among the 117 patients who were clinical N1 cases, 53 (45.3\%) were found to have positive nodes on histopathology and 64 (54.7\%) were false. Level I lymph node metastasis $(77.3 \%)$ was seen in majority of the oral cancers. After mean follow-up of 30 months, 71 patients are alive and disease-free, twelve patients had local and six $(5.1 \%)$ had nodal recurrences.

Conclusion: Supraomohyoid neck dissection in locally advanced oral malignancies with $\mathrm{N} 1$ neck, carries low morbidity and complications and is effective substitute for modified radical neck dissection in suitable cases. Postoperative radiotherapy improves the outcome.

Keywords: N1 neck, Oral cancer, Supraomohyoid neck dissection.

How to cite this article: Harshita TR, Mohiyuddin SMA, Sagayaraj A, Suresh TN, Merchant S. Effectiveness of Supraomohyoid Neck Dissection in Oral Cancers with N1 Neck. Int J Head Neck Surg 2015;6(2):73-75.

Source of support: Nil

Conflict of interest: None

\section{INTRODUCTION}

Worldwide estimate of oral cancer detection each year is $4,05,000$ cases with $2 / 3$ rd occurring in developing

\footnotetext{
${ }^{1}$ Postgraduate, ${ }^{2}$ Professor and Head

${ }^{3}$ Associate Professor, ${ }^{4}$ Professor, ${ }^{5}$ Assistant Professor

${ }^{1-3,5}$ Department of Otorhinolaryngology, Sri Devaraj Urs Medical College, Kolar, Karnataka, India

${ }^{4}$ Department of Pathology, Sri Devaraj Urs Medical College Kolar, Karnataka, India

Corresponding Author: TR Harshita, Postgraduate, Department of Otorhinolaryngology, Sri Devaraj Urs Medical College, Kolar Karnataka, India, Phone: 9945254872, e-mail: harshiblissful@ gmail.com
}

countries. Oral cancer ranks among the top three types of cancers in India. ${ }^{1}$

In the western world, the tongue and floor of the mouth are the most common sites of origin for primary squamous cell carcinoma in the oral cavity. However, in India, the buccal mucosa and retromolar trigone are the most frequently encountered primary sites owing to poor oral hygiene in our patients. ${ }^{2}$

The presence of lymph node metastasis in squamous carcinoma of oral cavity is the most important prognostic factor. ${ }^{3}$ Traditionally, modified radical neck dissection has been done for $\mathrm{N} 1$ cases. In this regard, previous studies have shown that the most common sites for metastases of oral tongue cancer were at levels I and II. ${ }^{4}$ Buccal mucosa cancers are not aggressive unlike tongue cancers. Clinically positive lymph nodes turns out to be reactive most of the times. The term supraomohyoid neck dissection (SOND) refers to the removal of lymph nodes contained in levels I to III. Usually, SOND has been employed as elective neck dissection for the initial management of neck in patients who have no clinical evidence of lymph node metastasis. The goal of the SOND is to remove the nodes which are at risk while preserving the function and minimizing morbidity. Therefore, we conducted a study to evaluate the oncological outcome after SOND in patients with oral cancers with clinically N1 neck.

\section{MATERIALS AND METHODS}

In this retrospective study, we analyzed medical records of 117 patients of oral cavity squamous cell carcinoma with clinically N1 neck between 2007 and 2012. All the patients underwent SOND along with composite resection and reconstruction of defects wherever required after obtaining the written informed consent in RL Jalappa Hospital and Research Centre in Kolar, Karnataka, India (Fig. 1). All these patients were operated by the same surgeon to eliminate bias. Patients who had undergone earlier treatment for cancer (surgical or radiotherapy or neoadjuvant chemotherapy) were excluded from the study. The oncological levels of various lymph nodes were marked on the specimen (Fig. 2). The specimen was evaluated by histopathology and lymph nodes having metastasis and their level was documented. Patients who had T4a tumors or T3 with close margins, deep infiltration, multiple metastatic nodes and extracapsular spread 


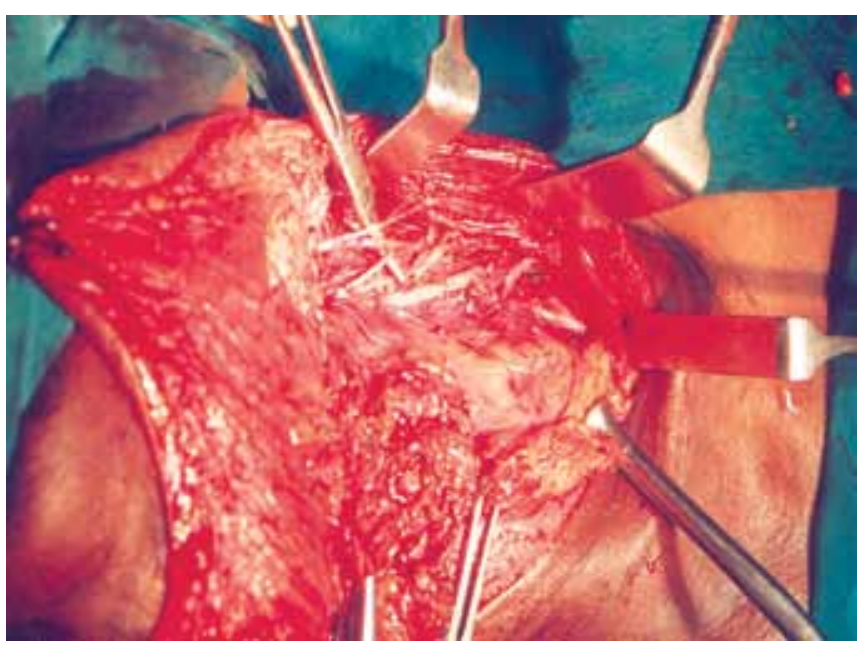

Fig. 1: Intraoperative

in lymph nodes were administered radiotherapy. Then, the patients were followed up periodically for minimum 2 years.

\section{RESULTS}

A total of 117 patients, who underwent wide excision and supraomohyoid neck dissection for N1 were included. Pathological reports were studied and neck node status was determined. Majority of our patients were females (73.5\%) owing to their habit of tobacco chewing. The site in these patients included 93 buccal mucosa, five upper alveolus, five anterior tongue, six lower alveolus, four retromolar trigone, two lips and one floor of mouth (Table 1). Predominantly, in our series, buccal mucosa cancers followed by the lower alveolus cancers were included.

According to AJCC TNM staging system, 48 cases were classified as T2, 58 as T3 and 11 as T4. Among the 117 patients who were clinical N1 cases, $53(45.3 \%$ ) were found to have positive nodes on histopathology and 64 (54.7\%) were false positive cases (Table 2). Most of the metastasis was found to be in level I lymph node (Table 3).

Postoperative radiotherapy was given to the neck sites of 65 patients, including those who had pathological

Table 1: Subsites of oral cancer

\begin{tabular}{ll}
\hline Site & $n=117$ \\
\hline Buccal mucosa & $93(79.5 \%)$ \\
Upper alveolus & $5(4.3 \%)$ \\
Lower alveolus & $6(5.2 \%)$ \\
Anterior tongue & $5(4.3 \%)$ \\
Retromolar trigone & $4(3.4 \%)$ \\
Lips & $3(2.6 \%)$ \\
Floor of mouth & $1(0.8 \%)$ \\
\hline
\end{tabular}

Table 2: Pathologically positive nodes

\begin{tabular}{ll}
\hline Pathological positive nodes & $53 / 117$ \\
Showing metastasis (true positive) & $45.3 \%$ \\
Reactionary lymph nodes (false positive) & $54.7 \%$ \\
\hline
\end{tabular}

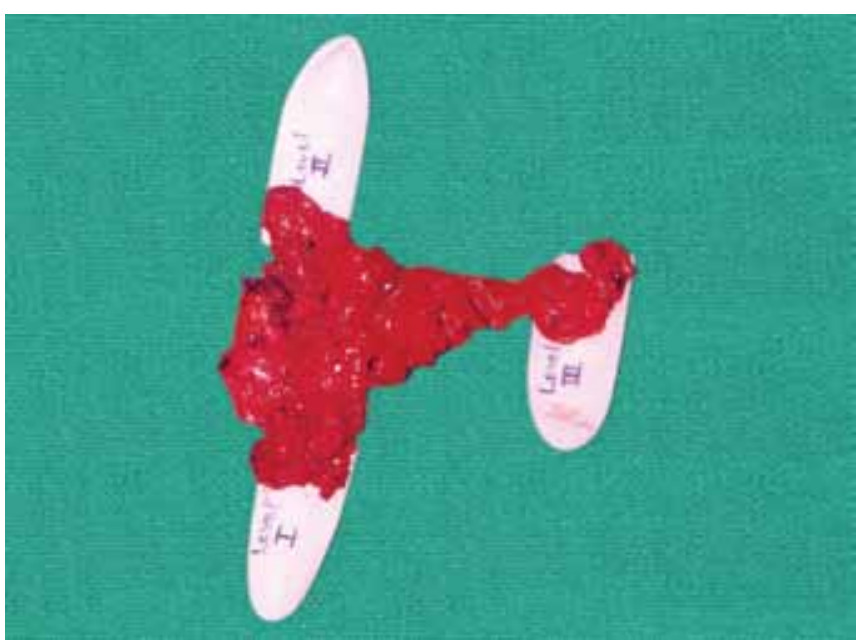

Fig. 2: Excised specimen

$\mathrm{N}+$ nodes, perineural invasion, close surgical margin or advanced primary tumor. Among those patients who had metastasis on histopathology, six had nodal recurrences. The nodal recurrences occurred within a range of 6 to 18 months. Among the nodal recurrence cases, initially during surgery, four patients with clinical N1 had enlarged nodes at level I and two patients had clinical N1 had enlarged nodes at level II. Twelve patients had local recurrence. All the nodal recurrences were within the area of prior SOND site. Five out of six patients who had nodal recurrence had pathological N2b status (level I + II or level II + III). Two patients were salvaged with radical neck dissection. Two of the remaining four patients who were not salvaged with radical neck dissection died due to uncontrolled neck disease, one patient is alive and the other one patient was lost to follow-up. Two out of five patients who were advised postoperative radiotherapy refused. Three patients developed distant metastasis in the lung (Table 4).

\section{DISCUSSION}

Crile first systematically described the radical neck dissection in $1906 .{ }^{5}$ Long-term morbidity were associated with

Table 3: Level of the lymph nodes positive on histopathology/pathology

\begin{tabular}{ll}
\hline Level I & $41(77.3 \%)$ \\
Level II & $4(7.54 \%)$ \\
Levels I and II & $5(9.4 \%)$ \\
Levels II and III & $3(5.6 \%)$ \\
\hline
\end{tabular}

Table 4: Postoperative follow-up

\begin{tabular}{ll}
\hline Alive and disease-free & 76 \\
Local recurrence & 12 \\
Regional recurrence & 6 \\
Distant metastasis & 3 \\
Died due to other causes & 4 \\
Lost to follow-up & 6 \\
\hline
\end{tabular}


this method. Studies later done showed the predictability of the site of lymph node metastasis. The pattern of lymph node spread in oral cancers described by Lindberg was the rationale for SOND. The highest risk for metastasis was documented in levels I, II and III and metastasis to levels IV and V is extremely low. ${ }^{4}$ Study by Shah and his team showed only $9 \%$ incidence of positive nodes in level IV. And, the incidence of level V was only $2 \% .{ }^{6}$ In our group, majority of the patients, 41 had metastasis in level I, four patients had isolated metastasis in level II and 3 had metastasis in level III. Floor of the mouth and tongue had metastasis in level III. As most of our cases involved buccal mucosa metastasis to level III was rare. In our group, $53.7 \%$ of clinically N1 were found to be pathologically node negative on histopathology. This could be due to poor oral hygiene with ulcerated growth and super added component of infection resulting in clinically palpable nodes with reactive hyperplasia. This similar pattern was observed in a study done in Taiwan. ${ }^{7}$

Though the rate of metastasis to all level increases with $\mathrm{N}+$ disease, the pattern of involvement is similar to N0. A similar study reported $94.3 \%$ regional control rates in node positive patients undergoing SOND. ${ }^{8}$ Kowalski and their group did not find positive nodes in level IV or V. ${ }^{9}$ After mean follow-up of 30 months, 76 patients in our study are alive and disease-free. Six (5.1\%) of our patients had neck recurrence. None of our patients had metastasis to level IV. Medina in his study noted a similar failure rate of $12.5 \%$ in $\mathrm{N}+$ patients undergoing SOND. ${ }^{10}$ Various studies with 20 to 50 patients having N1 disease reported recurrence rates of 4 to $6 \% .{ }^{11-13}$ Padedar in his review article has recommended that patients with $\mathrm{N}+$ disease may undergo dissection of levels I, II, III and IV. His review included studies on oropharyngeal lesions. ${ }^{14}$

Postoperative radiotherapy was recommended in 65 patients, who had pathological positive nodes, extracapsular spread, perineural invasion, close margins and advanced stage of the disease. Five of the six nodal recurrence cases were advised for postoperative radiotherapy, two of these patients defaulted. The failure rate improved with postoperative radiotherapy. This view is supported by Ambrosch et al in their study. ${ }^{15}$

\section{CONCLUSION}

Supraomohyoid neck dissection is oncologically safe in therapeutic management of cervical lymph nodes. This is true especially for buccal mucosa cancers as they metastasize mostly to levels I and II. The regional control after
SOND is comparable to modified radical neck dissection. Supraomohyoid neck dissection when done for cases with N1 neck avoided the morbidity associated with modified radical neck dissection. Addition of postoperative radiotherapy improves the prognosis.

\section{REFERENCES}

1. Ganly I, Ibrahimpasic T, Patel SG, Shah JP. Tumors of the oral cavity. In: Montgomery PQ, Evans PHR, Gullane PJ, editors. Principles and practice of head and neck surgery and oncology. 2nd ed. London: Informa Healthcare; 2009. p 160-171.

2. Shah JP, editor. In: Oral cavity and oropharynx. Head and Neck Surgery. 2nd ed. New York: Mosby Wolfe; 1996. p. 167-234.

3. Rassekh CH, Johnson JT, Myers EN. Accuracy of intraoperative staging of the N0 neck in squamous cell carcinoma. Laryngoscope 1995;105(12):1334-1336.

4. Lindberg R. Distribution of cervical lymph node metastasis from squamous cell carcinoma of the upper respiratory and digestive tracts. Cancer 1972;29(6):1146-1149.

5. Crile GW. Excision of cancer of the head and neck. JAMA 1906;47(22):1780-1786.

6. Shah JP. The patterns of cervical lymph node metastasis from squamous cell carcinoma of the upper aerodigestive tract. Am J Surg 1990;160(4):405-409.

7. Liaw GA, Yen CY, Chiang WF, Lee CH, Yang C, Chiou CT, et al. Outcome of treatment with total main tumor resection and supraomohyoid neck dissection in oral squamous cell carcinoma. Formos Med Assoc 2006;105(12):971-976.

8. Andersen PE, Warren F, Spiro J, Buringham A, Wong R, Wax MK, et al. Results of selective neck dissection in management of the node positive neck. Arch Otolaryngol Head Neck Surg 2002;128(10):1180-1184.

9. Kowalski LP, Carvalho AL. Feasibility of supraomohyoid neck dissection in N1 and N2a oral patients. Head Neck 2002;24(10):921-924.

10. Medina JE, Byers RM. Supraomohyoid neck dissection: rationale, indications and surgical technique. Head Neck 1989;11(2):111-122.

11. Pathak KA, Das AK, Agarwal R, Talole S, Deshpande MS, Chaturvedi $\mathrm{P}$, et al. Selective neck dissection (I-III) for node negative and node positive necks. Oral Oncol 2006;42(8): 837-841.

12. Spiro RH, Morgan GJ, Strong EW, Shah JP. Supraomohyoid neck dissection. Am J Surg 1996;172(6):650-653.

13. Traynor SJ, Cohen JI, Andersen PE, Everts EC. Am J Surg 1996;172(6):654-657.

14. Padedar NA, Gilbert RW. Selective neck dissection: a review of evidence. Oral Oncol 2009;45(4):416-420.

15. Ambrosch P, Kron M, Pradier O, Steiner W. Efficacy of selective neck dissection: a review of 503 cases of elective and therapeutic treatment of the neck in squamous cell carcinoma of the upper aerodigestive tract. Otolaryngol Head Neck Surg 2001;124(2):180-187. 